\title{
Identification and Quantification of Flavonoids in Korean Wild Grape (Meoru grape, Vitis coignetiae) and Its Pomace
}

\author{
Kwan-Seob Shim ${ }^{1}$, Da-Rae Kang ${ }^{1}$, Seong-Bok Park², Jong Hyuk Park ${ }^{3}$, Yi Hyung Chung ${ }^{4}$, \\ Young-Hee Kang ${ }^{5}$ and Daekeun Shin ${ }^{5}$ * \\ ${ }^{1}$ Department of Animal Biotechnology, Chonbuk National University, Jeonju 561-756, Korea \\ ${ }^{2}$ National Institute of Animal Science, RDA, Namwon 590-830, Korea \\ ${ }^{3}$ Institute of Natural Medicine, Hallym University, Chuncheon 200-702, Korea \\ ${ }^{4}$ Jeonbuk Institute for Bioindustry, Jeonju 561-360, Korea \\ ${ }^{5}$ Department of Food and Nutrition, Hallym University, Chuncheon 200-702, Korea
}

\begin{abstract}
Large quantities of Korean wild grape (Vitis coignetiae, KWG) pomace, a by-product of grape juice and wine manufacture, are generated annually, and disposal cost of KWG pomace is now increasing. Therefore, this study was conducted to determine total polyphenol, flavonoid, and anthocyanin content in whole KWG, KWG skin and KWG pomace and to identify and quantify flavonoids found in whole KWG and KWG pomace using LC/MS/MS. Spectral analysis showed high total polyphenol and flavonoid in KWG skin extracted with 75\% ethanol $(p<0.05)$. KWG pomace had higher amount of total polyphenol, flavonoid and anthocyanin than whole grape $(p<0.05)$. Sixteen flavonoids were identified, but only 10 flavonoids were quantifiable from whole KWG and KWG pomace. Both epicatechin and rutin were the major flavonoids, and 521 or $147 \mathrm{ng} / \mathrm{g}$ of epicatechin $(p<0.05)$ and 305 or $110 \mathrm{ng} / \mathrm{g}$ of rutin $(p>0.05)$ were found in whole KWG and KWG pomace, respectively. The results show that KWG pomace is a very rich source of flavonoids, thus KWG pomace can be used as a functional food additive. Plans to include KWG pomace in food production are necessary.
\end{abstract}

Key words - By-product, Ethanol, Korean wild grape skin, LC/MS/MS, Polyphenol

\section{Introduction}

As consumers' demand for health benefits via food consumption increases, interests for phytochemicals of fruits and vegetables are elevated. The polyphenols, a group of phytochemical containing more than one phenolic group, have anti-microbial, anti-oxidant and anti-inflammatory effects (Ruberto et al., 2007; Stevenson and Hurst, 2007; Shin et al., 2011; Gong et al., 2012; 2014), and it seems that they improve foods quality and then consumers' health as a result. Shin et al. (2011) reported that the addition of sorghum bran with vitamins $\mathrm{C}$ and $\mathrm{E}$ in chicken thigh meat sausages decelerates the lipid oxidation. Either or both hydrophilic and/or hydrophobic polyphenols of sorghum bran seems to contain major compounds providing an electron to reactive oxygen species (ROS) directly or an electron to pro-vitamins $\mathrm{C}$ and $\mathrm{E}$

${ }^{*}$ Corresponding author. E-mail : aceflavor@hotmail.com for electron restoration. In addition, based on the literature evidences, both kaempferol and resveratrol, flavonoids or stilbenoids of grapes, seem to attenuate allergic responses when either was offered to BALB/c up to $10-20 \mathrm{mg} / \mathrm{kg}$ (Gong et al., 2012, 2014; Han et al., 2013). Therefore, efforts to investigate polyphenol content of fruits and vegetables are now progressing, and making polyphenol identification and quantification of traditional Korean wild grape (Meoru grape, Vitis coignetiae, $\mathrm{KWG}$ ) is necessary.

Grape is one of the world's most common fruits, containing high amounts of polyphenols, include flavonoids, and about 67 million tons are produced each year due to the FAOSTAT database (FAO STAT, 2014). As grapes are harvested, they are used for juice or wine production in Asia and Europe. Around $20 \%$ of the grapes particularly seeds and skins, remains as a residue after grapes are crushed and pressed during juice and wine manufacture (Amico et al., 2004; Llobera and Cañellas, 2007; Ruberto et al., 2007). Disposal cost of 
grape residues which are now called grape pomace, is increasing. To control these costs, some of the grape pomace is disposed as soil compost and animal feed (Negro et al., 2003; Kammerer et al., 2005; Khanal et al., 2010). Furthermore, in spite of the high content of polyphenols in grape pomace, only a small amount of the grape pomace is used as food materials in the manufacture of vinegar and grappa (Lu and Foo, 1999; Özkan et al., 2004; Ruberto et al., 2007; Monrad et al., 2010). Qualitative and quantitative polyphenols of grape pomace are important to produce quality vinegar and grappa, and different qualities of the pomace depend on the grape variety, cultivar, and cultivation district (Tourtoglou et al., 2014). Both qualitative and quantitative polyphenols of grape pomace should be determined before creating KWG pomace as a novel food material.

Therefore, as the first step, this study focused on the identification of flavonoids and non-flavonoids in Korean wild grape (KWG) pomace and when possible, quantification of major flavonoids through LC/MS/MS was performed. Also, spectral analysis for total polyphenol, flavonoid and anthocyanin contents of KWG pomace was examined to determine the nutritional value of grape pomace as a food material.

\section{Materials and Methods}

\section{Sample preparation}

De-stemmed KWGs (Yeongdong meoru grape, Vitis coignetiae), which are native and widely grown in Republic of Korea, were purchased from a local nonghyup-mart in Jeonju (September 2013). Some whole KWGs were immediately freeze-dried, powdered and stored at $-20^{\circ} \mathrm{C}$ for analysis. Others were processed to generate grape skin and grape pomace. Grape skins or grape pomaces (grape skins with seeds only) without grape stems, were pressed and collected after juicing (Hurom Group Co., Gimhae, Kyeongnam, Korea). Each grape skin or grape pomace was then vacuum freeze-dried (Ilshinbiobase Co. Ltd., Yangju, Gyeonggi, Korea) for 2 days, powdered by a grinder (Ya Hong Electronic Co., Guangdong, China) for $1 \mathrm{~min}$ and then stored at $-20^{\circ} \mathrm{C}$ in a freezer (LG electronics., Seoul, Korea). Three different samples of whole grape, grape skin, and grape pomace, were collected and provided for analysis. Individual sample was analyzed on a duplicate basis.

\section{Determination of phenolic compounds}

$10 \mathrm{~g}$ of whole grape, grape skin and grape pomace powder were sampled for total polyphenol determination. The total soluble polyphenols was extracted with $90 \mathrm{ml}$ of either $100 \%$ or $75 \%$ ethanol at $4{ }^{\circ} \mathrm{C}$ for $24 \mathrm{hr}$ with continuous shaking at 200 rpm (Vision Scientific Co., Daejeon, Korea). Each extract was filtered, and $0.1 \mathrm{ml}$ of each sample extract was assigned to individual tube containing $1.0 \mathrm{ml}$ of Folin-Ciocalteu reagent (1:10 v/v with water) (Anesini et al., 2008; Park et al., 2012). Then, $0.3 \mathrm{ml}$ sodium carbonate $(75 \mathrm{~g} / \mathrm{L})$ was added. Each tube was then incubated at room temperature for $90 \mathrm{~min}$, and the absorbance at $765 \mathrm{~nm}$ was read against a blank containing respective solvent. All results were then compared to gallic acid $(\mathrm{mg} / \mathrm{g})$ as a standard.

$0.5 \mathrm{ml}$ of whole grape, grape skin or grape pomace extract prepared as discussed above, was mixed with $1 \mathrm{~mL}$ of $10 \mathrm{mM}$ Tris $\mathrm{HCl}(\mathrm{pH} 7.0)$ and $75 \mu \mathrm{l}$ of $5 \%$ sodium nitrite (Juan and Chou, 2010). After incubation for $6 \mathrm{~min}$ at room temperature, $150 \mu \mathrm{l}$ of $10 \%$ aluminum chloride, $500 \mu \mathrm{l}$ of $1 \mathrm{M}$ sodium hydroxide and $275 \mu \mathrm{l}$ of double distilled water (DDW) were added and thoroughly mixed. The spectrometric absorbance of each sample solution was measured at $510 \mathrm{~nm}$, and the total flavonoid of whole grape, grape skin and grape pomace was calibrated using quercetin $(\mathrm{mg} / \mathrm{g})$ as a standard.

$0.1 \mathrm{~g}$ freeze-dried whole grape, grape skin, and grape pomace were mixed with $10 \mathrm{ml}$ of ethanol:DDW: $\mathrm{HCl}(85: 13: 2, \mathrm{v}: \mathrm{v}: \mathrm{v})$ (Jang et al., 2008). The sample mixture was incubated at $15^{\circ} \mathrm{C}$ for $24 \mathrm{hr}$ with continuous shaking at $220 \mathrm{rpm}$ and then filtered. The absorbance of the whole grape, grape skin and grape pomace was measured at $535 \mathrm{~nm}$. The amount of anthocyanin was then calculated as follows:

Total anthocyanin contents $(\mu \mathrm{g} / \mathrm{g})=\left[\right.$ Absorbance $_{535} \times$ Extractant $(\mathrm{ml})] /$ Sample $(\mathrm{g}) \times[1 / 65.1]($ Absorption Coefficient)

\section{Determination of water content and $\mathrm{pH}$}

Whole KWG and grape pomace were tested for water content and $\mathrm{pH}$. Water content of whole grape and grape pomace was obtained by finding the weight difference before and after lyophilization (\%). $10 \mathrm{~g}$ of whole grape or grape 
pomace powder in $90 \mathrm{ml} \mathrm{DDW}$ was homogenized, filtered, and tested with a pH meter (Corning Inc., NY, USA), which had been calibrated with a standard buffer of $\mathrm{pH} 7$. Duplicate readings for each sample were conducted, and the average was reported.

\section{LC/MS/MS analysis of flavonoid compounds}

Sample preparation for flavonoid determination was performed by addition of $90 \mathrm{ml}$ ethanol (100 or $75 \%$ ) to $10 \mathrm{~g}$ of whole grape, grape skin, and grape pomace powder in a brown colored glass bottle. The mixture was incubated at 1 $5^{\circ} \mathrm{C}$ for $24 \mathrm{hr}$ with continuous shaking at $150 \mathrm{rpm}$ and then filtered. The aqueous mixture was concentrated on the rotary evaporator under reduced pressure at room temperature. The extract was then passed through an activated C18 $\left(60 \mathrm{~cm}^{3} / 10 \mathrm{~g}\right)$ Mega Bond Elute cartridge (Supelco, Bellefonte, PA, USA). The cartridge was rinsed with water to remove sugars and simple organic acids. The phytochemicals retained, were then eluted with $100 \%$ ethanol. Individual $5 \mu$ liquid samples were directly injected to the liquid chromatography (Agilent Technologies, Palo Alto, CA, USA) system coupled with an electrospray ionization-mass spectrometer (ESI-MS/MS) detector. The chromatographic separation was achieved with a Phenomenex synergy Hydro-RP $(2.1 \mathrm{~mm}$ i.d. $\times 150 \mathrm{~mm}$, Phenomenex, Torrance, CA, USA) followed by $0.2 \mathrm{ml} / \mathrm{min}$ of flow under $400 \mathrm{psi}$ at $30^{\circ} \mathrm{C}$. The gradient elution composed of $0.1 \%$ formic acid (A) in water and $0.1 \%$ formic acid acetonitrile (B), 5\% B linear gradient (min 0-1); 5-100\% B linear gradient (min 1-10); 100\% B (min 10-11); 100-5\% B linear gradient (min 11-14); 5\% B (min 14-20). The column was re-conditioned for $15 \mathrm{~min}$ before the next run.

The peaks were identified by comparison of retention time (RT) and mass spectra (MS) with references. All reference compounds including apigenin (lot no. SLBG8924V), benzoic acid (lot no. MKBL6689V), caffeic acid (lot no. MKBQ5343V), catechin (hydrate) (lot no. BCBK7891V), cyanin chloride (lot no.BCBL3222V), epicatechin (lot no.SLBH5965V), epigallocatechin (lot no. SLBG2332V), epigallocatechin gallate (lot no. SLBG6681V), gallic acid (lot no. SLBF8212V), gallocatechin (lot no. SLBH7895V), isorhamnetin (lot no. BCBK2503V), isovanillic acid (lot no. 1419575V), kaempferol (lot no. BCBM7287V), luteorin (lot no. 083M4090V), myricetin (lot no. BCBL4930V), naringenin (lot no. BCBJ2179V), pelargonidin chloride (lot no. SLBF4330V), quercetin (lot no. SLBD8415V), quercetin 3-D-galactoside (lot no. BCBH6299V), rosmarinic acid (lot no. SLBG3402V) and rutin (trihydrate) (lot no. 1380505V), were purchased from Sigma Chemical Company. Multiple reactions monitoring (MRM) transition of each reference was used for quantitative analysis of compounds in whole grape and grape pomace. Each reference compound was used for preparation of calibration at concentrations between 1 and $1000 \mathrm{ng} / \mathrm{ml}$. The grape skin was employed for kaempferol determination only (Table 3).

\section{Statistical analysis}

Statistical analysis was conducted using a SAS program (Version 6.12, Cary, NC, USA, 1998) (SAS, 1998), and significant difference was determined by an Analysis of Variance (ANOVA) using GLM procedure, followed by a Duncan's Multiple Range Test with a predetermined significance level of $p<0.05$.

\section{Results and Discussion}

\section{Phenolic composition of whole grape, grape skin and grape pomace}

Total polyphenols and flavonoids expressed as $\mathrm{mg} / \mathrm{g}$ of KWG skin, were determined by the Folin-Ciocalteu reagent, and the results are presented in Table 1. From comparison of the literature on the yield of phenols from grape, phenols were high when $\sim 30 \%$ water was mixed with ethanol and then used as a solvent (Spigno et al., 2007; Monrad et al., 2010) unless both flavonols and anthocyanins are less soluble in water than in an organic media (Corrales et al., 2008). As evidenced, both total polyphenols and flavonoids were significantly higher when extracted in $75 \%$ ethanol solvent ( 1.15 or $1.08 \mathrm{mg} / \mathrm{g}$ of grape skin, respectively) ( $p<0.05)$. Most polyphenols of grape skin are flavonoids, covering $94 \%$ of polyphenols. Actual flavonoid versus polyphenol ratio of KWG was high in comparison to that of Bulgarian whole black grape (Witis vinifera), which Marinova et al. (2005) found to be $0.36 .75 \%$ ethanol showed lower kaempferol than $100 \%$ ethanol extractant albeit the content was not significantly different $(p>0.05)$. The amount of anthocyanin detected, was 
less than total polyphenols and flavonoids, and it is similar to the results demonstrated by Negro et al. (2003), showing $1.40,1.31$ and $0.33 \mathrm{~g} / \mathrm{L}$ of total polyphenol, flavonoid and anthocyanin in red grape, respectively.

When whole grape and grape pomace were freeze-dried, moisture content was 79.46 and $54.41 \%$, respectively $(p<$ 0.05 ) (Table 1), and these are lower than the moisture of whole grape (96.19\%) and grape pomace (73.65-80.12\%) of Vitis vinifera ssp. reported by Corrales et al. (2008). The $\mathrm{pH}$ value of whole grape was 4.00 and then elevated to 4.41 when whole grapes were pressed and turned to grape pomace $(p<$ $0.05)$.

All polyphenols were significantly higher in grape pomace than in whole grape $(p<0.05)$ (Table 1$)$. The amount of polyphenols and flavonoids was elevated in grape pomace and is 2.30 time higher than that of whole grape, which is in agreement with Butkhup et al. (2010). Unexpectedly, grape pomace posed high concentration of anthocyanins when exactly equal amount of whole grape and grape pomace were weighed and analyzed. Khanal et al. (2009) reported that anthocyanin of whole grape is lower during juice mashing steps and substantial amounts of anthocyanins are lost due to elution as a form of grape juice (Kammerer et al., 2004; Wu et al., 2006; Monrad et al., 2010). However, Maier et al. (2009) and Pinelo et al. (2006) suggested that anthocyanin deficiency is depending on the pectin and/or sugar of the grape, and it is clear that the anthocyanin of grape pomace seems closely related to water loss due to grape cell wall damage. Without complete destruction of pectin structure and/or loss of phenol-sugar binding, anthocyanin may be eluted as a form of grape juice less than expected (Kennedy and Matthews, 2002; Pinelo et al., 2006; Maier et al., 2009). Anthocyanin of grape pomace was not the lost and retained $12.42 \mu \mathrm{g} / \mathrm{g}$, indicating grape itself, being deprived of grape skin and seed, may not be a good source of polyphenol due to high content of polyphenols in grape skin and seed (Pinelo et al., 2006). According to the study of Ruberto et al. (2007), general Italian grape possessed greater total anthocyanin than flavonoid. However, the amount of anthocyanin was not greater than flavonoid in KWG. The amount of flavonoid and anthocyanin of KWG pomace are $6.54 \mathrm{mg} / \mathrm{g}$ and $12.42 \mu \mathrm{g} / \mathrm{g}$, respectively.

\section{Flavonoids and non-flavonoids identification}

Flavonoid and non-flavonoid profiles of whole grape and grape pomace were checked and identified (Table 2). Twentyone peaks were identified and were mostly flavan-3-ols, flavanone, flavone, flavonol and phenolic acids (non-flavonoids). In whole grape and grape pomace, catechin (hydrate), epigallocatechin, epicatechin, epigallocatechin gallate, gallocatechin were recognized as a group of flavan-3-ols (Yilmaz and Toledo, 2004), which are generally from grape skin and seed (Lee et al., 2003; Kammerer et al., 2004; Pinelo et al., 2006). Naringenin which reduces plasma and hepatic cholesterol by suppressing HMG-CoA reductase activity (Panoutspopoulos and Beedham, 2005; Chang et al., 2011), was the only flavanone confirmed in both whole grape and grape pomace. As sub-groups of anthoxanthins, 8 flavones and flavonols were identified, (flavones: apigenin, luteorin, quercetin 3-D-galactoside and rutin; flavonols: myricetin, isorhamnetin, quercetin and kaempferol, respectively). Isovanillic acid, a non-flavonoid and a metabolized form of isovanillin by aldehyde dehydrogenase (Revilla and Ryan, 2000), was distinguished. Moreover, benzoic acid, caffeic acid, gallic acid, and rosmarinic acid, non-flavonoids, were found in either whole grape or grape pomace, which is similar to those found in the Vitis vinifera L. of Germany and USA and Shiraz red grape of Thailand (Lee et al., 2003; Kammerer et al., 2004; Butkhup et al., 2010).

\section{Flavonoids quantification}

The chromatographic fingerprint of flavonoids from whole grape and grape pomace was analyzed by LC/MS/MS. Using 16 different flavonoids as standards, 10 flavonoids were quantified by LC/MS/MS in both or either whole grape (Fig. 2) and grape pomace (Fig. 3). Those were cyanin chloride, epigallocatehcin, epicatechin, gallocatechin, naringenin, quercetin 3-D-galactoside, rutin (trihydrate), isorhamnetin, myricetin, and quercetin. Among them, epicatechin, rutin and myricetin were the main flavonoids quantified by LC/MS/ MS (Fig. 1), which is not consistent with Amico et al. (2004). Amico et al. (2004) reported that quercetin was the main flavonoid of Nerello Mascalese grape pomace followed by isorhamnetin. Both whole grape and grape pomace contained 521.69 and $147.58 \mathrm{ng} / \mathrm{g}$ of epicatechin and 305.45 and 110.94 


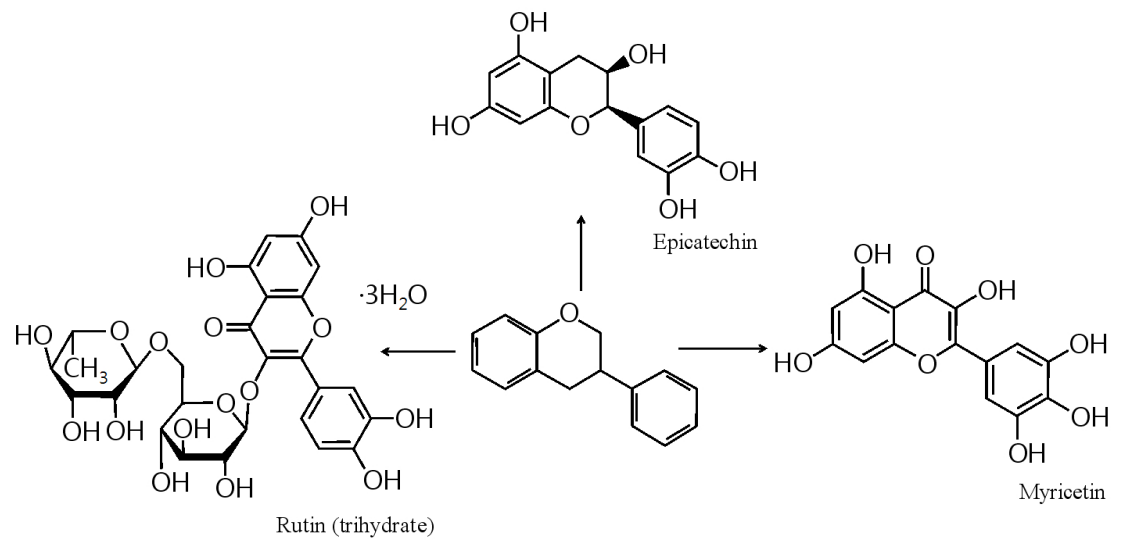

Fig. 1. Three different major flavonoids observed in both whole Korean wild grape and grape pomace.
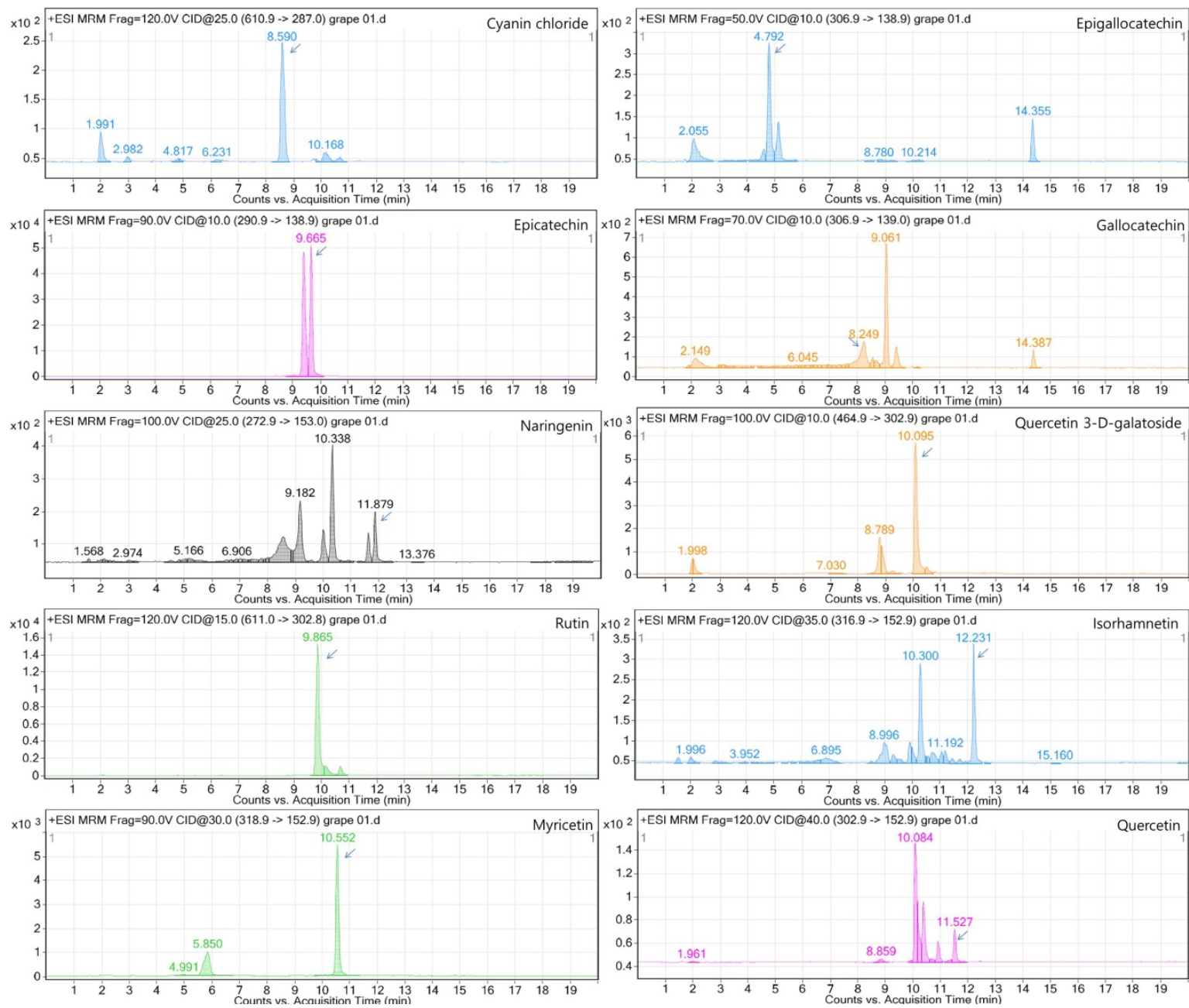

Fig. 2. Flavonoids quantification of whole Korean wild grape using LC/MS/MS.

*Cyanin chloride (610.9-287.0;8.59), epigallocatechin (306.9-138.9;4.792), epicatechin (290.9-138.9;9.665), gallocatechin (306.939.0;8.249), naringenin (272.9-153.0;11.879), quercetin 3-D galactoside (464.9-302.9;10.095), rutin (611.0-302.8;9.865), isorhamnetin (316.9-152.9;12.231), myricetin (318.9-152.9;10.552), quercetin (302.9-152.9;11.527).

$* *$ Naringenin $=$ Not detected. 

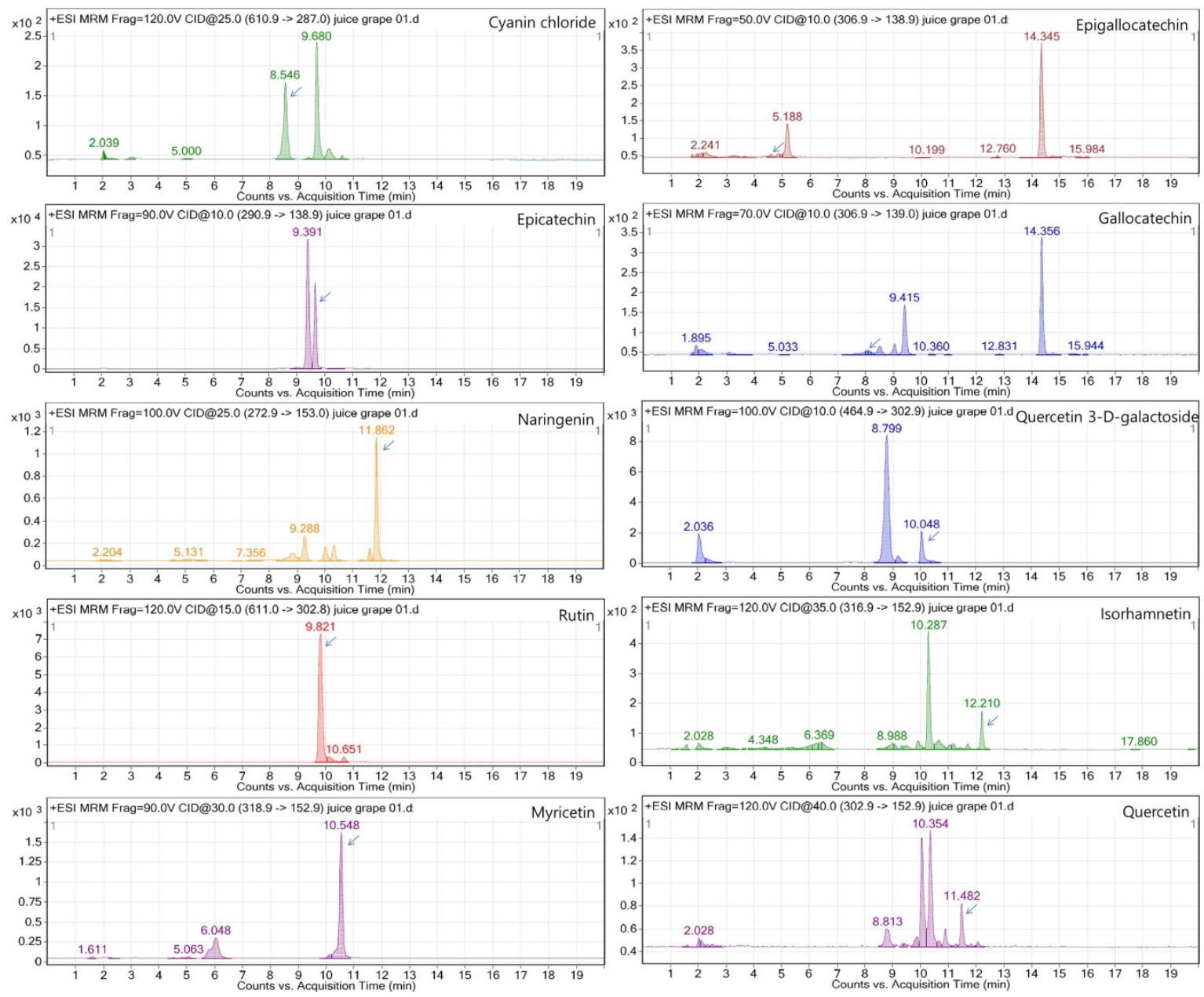

Fig. 3. Flavonoids quantification of whole Korean wild grape pomace using LC/MS/MS.

*Cyanin chloride (610.9-287.0;8.546), epigallocatechin (306.9-138.9;4.864), epicatechin (290.9-138.9;9.656), gallocatechin (306.9-139.0;8.052), naringenin (272.9-153.0;11.862), quercetin 3-D-galactoside (464.9-302.9;10.048), rutin (611.0-302.8;9.821), isorhamnetin (316.9-152.9;12.21), myricetin (318.9-152.9;10.548), quercetin (302.9-152.9;11.482).

**Epigallocatechin, Quercetin 3-D-galactoside = Not detected.

$\mathrm{ng} / \mathrm{g}$ of rutin, respectively, and these were mainly from grape seed or skin (Lacopini et al., 2008, Ratnasooriya et al., 2010). The content of epicatechin and rutin of KWG was similar to those of whole Shiraz red grapes in Thailand (Butkhup et al., 2010) but lower than the Shiraz red grape when KWGs were pressed and turned to pomace.

Whole grape contained $32 \%$ more water than grape pomace (Table 1), had higher amounts of epigallocatechin, epicatechin, gallocatechin, quercetin 3-D-galactoside, rutin (trihydrate), isorhamnetin, and myricetin compared to grape pomace (Table 4). Most flavonoids found in whole grape were 1.48-11.88 times higher than in grape pomace, which is not in agreement with
Ratnasooriya et al. (2010), showing higher flavan-3-ols in grape pomace. As mentioned above, both epigallocatechin and quercetin 3-D-galactoside seem to lost in grape juice (Meng et al., 2004) so neither epigallocatechin nor quercetin 3-D-galctoside was detectable in grape pomace. On the other hand, both naringenin and quercetin seemed to concentrate after grape juice and were 1-2 times greater in grape pomace. As quercetin is an antioxidant against both water and lipid soluble free radicals (Faustino et al., 2004), quercetin may not fully be soluble in water. Therefore, quercetin as well as naringenin is not easily eluted grape juice.

In conclusion, this study was carried out for spectral 
Table 1. Spectral analysis for total polyphenol, flavonoid and anthocyanin of whole Korean wild grape, grape skin and grape pomace and proximate water and $\mathrm{pH}$ of whole Korean wild grape and grape pomace

\begin{tabular}{|c|c|c|c|c|c|c|c|c|c|}
\hline & $\begin{array}{r}\text { Korean V } \\
\text { (Vitis }\end{array}$ & $\begin{array}{l}\text { rape skin } \\
\text { etiae) }\end{array}$ & & & & $\begin{array}{c}\text { Korean } \\
\text { (Vitis }\end{array}$ & $\begin{array}{l}\text { Grape } \\
\text { netiae) }\end{array}$ & $A^{z}$ & l \\
\hline & & & INI & $p$-value & & $100 \%$ & hanol & 1 & p-value \\
\hline & $100 \%$ & $75 \%$ & & & & Whole grap & rape pomace & & \\
\hline Polyphenol (mg/g) & $1.13^{\mathrm{b}}$ & $1.15^{\mathrm{a}}$ & 0.05 & 0.01 & Moisture (\%) & $79.46^{\mathrm{a}}$ & $54.41^{\mathrm{b}}$ & 4.18 & 0.01 \\
\hline & & & & & $\mathrm{pH}$ & $4.00^{\mathrm{b}}$ & $4.41^{\mathrm{a}}$ & 0.10 & 0.01 \\
\hline Flavonoid (mg/g) & $0.84^{\mathrm{b}}$ & $1.08^{\mathrm{a}}$ & 0.03 & 0.01 & Phytochemicals & & & & \\
\hline Kaempferol (ng/g) & 2.59 & 2.07 & 0.55 & 0.37 & Polyphenol (mg/g) & $2.94^{b}$ & $6.75^{\mathrm{a}}$ & 0.58 & 0.01 \\
\hline & & & & & Flavonoid (mg/g) & $2.86^{\mathrm{b}}$ & $6.54^{\mathrm{a}}$ & 0.48 & 0.01 \\
\hline Anthocyanin (ug/g) & & & 0.05 & - & Anthocyanin (ug/g) & $4.32^{\mathrm{b}}$ & $12.42^{\mathrm{a}}$ & 1.23 & 0.01 \\
\hline
\end{tabular}

${ }^{\mathrm{z}} \mathrm{SEM}=$ standard error of the mean.

${ }^{\mathrm{a}, \mathrm{b}}$ Mean values within a row followed by different letters indicate significant difference at $p<0.05$.

Table 2. Experimental parameters of LC/MS/MS for the detection of flavonoid in whole Korean wild grape and grape pomace

\begin{tabular}{|c|c|c|c|c|c|}
\hline Analyte & $\mathrm{MW}^{\mathrm{z}}$ & $\mathrm{RT}^{\mathrm{y}}$ & $\begin{array}{l}\mathrm{ESI}^{\mathrm{x}} \\
\text { mode }\end{array}$ & $\mathrm{MS}_{1}$ & $\mathrm{MS}_{2}$ \\
\hline Apigenin & 270.24 & 11.94 & {$[\mathrm{M}+\mathrm{H}]^{+}$} & 270.9 & 152.9 \\
\hline Benzoic acid & 122.12 & 11.84 & {$[\mathrm{M}-\mathrm{H}]^{+}$} & 121 & 77 \\
\hline Caffeic acid & 180.16 & 9.91 & {$[\mathrm{M}-\mathrm{H}]^{+}$} & 179 & 135.1 \\
\hline Catechin (hydrate) & 290.27 & 5.26 & {$[\mathrm{M}+\mathrm{H}]^{+}$} & 290.9 & 138.9 \\
\hline Cyanin chloride & 611.52 & 8.52 & {$[\mathrm{M}-\mathrm{H}]^{+}$} & 610.9 & 287 \\
\hline Epicatechin & 290.27 & 9.72 & {$[\mathrm{M}+\mathrm{H}]^{+}$} & 290.9 & 138.9 \\
\hline Epigallocatechin & 306.27 & 4.89 & {$[\mathrm{M}+\mathrm{H}]^{+}$} & 306.9 & 138.9 \\
\hline $\begin{array}{l}\text { Epigalloca- } \\
\text { techingallate }\end{array}$ & 458.37 & 9.82 & {$[\mathrm{M}+\mathrm{H}]^{+}$} & 458.9 & 138.9 \\
\hline Gallic acid & 170.12 & 3.91 & {$[\mathrm{M}-\mathrm{H}]^{+}$} & 169 & 125 \\
\hline Gallocatechin & 306.27 & 8.09 & {$[\mathrm{M}+\mathrm{H}]^{+}$} & 306.9 & 139 \\
\hline Isorhamnetin & 316.26 & 12.27 & {$[\mathrm{M}+\mathrm{H}]^{+}$} & 316.9 & 152.9 \\
\hline Isovanillic acid & 168.16 & 10.08 & {$[\mathrm{M}-\mathrm{H}]^{+}$} & 167 & 107.9 \\
\hline Kaempferol & 268.23 & 12.16 & {$\left[\mathrm{M}+\mathrm{H}_{2} \mathrm{O}\right]^{+}$} & 286.9 & 164.9 \\
\hline Luteorin & 286.24 & 11.26 & {$[\mathrm{M}+\mathrm{H}]^{+}$} & 286.8 & 134.9 \\
\hline Myricetin & 318.24 & 10.58 & {$[\mathrm{M}+\mathrm{H}]^{+}$} & 318.9 & 152.9 \\
\hline Naringenin & 272.26 & 11.89 & {$[\mathrm{M}+\mathrm{H}]^{+}$} & 272.9 & 153 \\
\hline $\begin{array}{l}\text { Pelargonidin } \\
\text { chloride }\end{array}$ & 271.24 & 10.02 & {$[\mathrm{M}-\mathrm{H}]^{+}$} & 270.9 & 121 \\
\hline Quercetin & 302.24 & 11.52 & {$[\mathrm{M}+\mathrm{H}]^{+}$} & 302.9 & 152.9 \\
\hline $\begin{array}{l}\text { Quercetin } \\
\text { 3-D-galactoside }\end{array}$ & 464.38 & 10.08 & {$[\mathrm{M}+\mathrm{H}]^{+}$} & 464.9 & 302.9 \\
\hline Rosmarinic acid & 360.31 & 10.07 & {$[\mathrm{M}-\mathrm{H}]^{+}$} & 359.1 & 161.1 \\
\hline Rutin (trihydrate) & 610.52 & 9.86 & {$[\mathrm{M}+\mathrm{H}]^{+}$} & 611 & 302.8 \\
\hline
\end{tabular}

Table 3. Regression equation and R-square of analytes for the detection of flavonoid in whole Korean wild grape and grape pomace

\begin{tabular}{lcc}
\hline \hline \multicolumn{1}{c}{ Analyte } & Regression equation & R square \\
\hline Apigenin & $\mathrm{Y}=119.83 \mathrm{x}+5020.7$ & 0.9974 \\
Benzoic acid & $\mathrm{Y}=0.0533 \mathrm{x}+1.6667$ & 1 \\
Caffeic acid & $\mathrm{Y}=29.872 \mathrm{x}+875.5$ & 0.9949 \\
Catechin (hydrate) & $\mathrm{Y}=55.559 \mathrm{x}+1090.7$ & 0.9993 \\
Cyanin chloride & $\mathrm{Y}=104.16 \mathrm{x}+931.4$ & 0.9996 \\
Epicatechin & $\mathrm{Y}=77.954 \mathrm{x}+948.56$ & 0.9997 \\
Epigallocatechin & $\mathrm{Y}=66.903 \mathrm{x}+1050.5$ & 0.9988 \\
Epigallocatechingallate & $\mathrm{Y}=62.909 \mathrm{x}+682.02$ & 0.9992 \\
Gallic acid & $\mathrm{Y}=11.215 \mathrm{x}+118.5$ & 0.9997 \\
Gallocatechin & $\mathrm{Y}=35.732 \mathrm{x}+16.444$ & 1 \\
Isorhamnetin & $\mathrm{Y}=55.739 \mathrm{x}+790.47$ & 0.9989 \\
Isovanillic acid & $\mathrm{Y}=0.1794 \mathrm{x}+11.333$ & 1 \\
Kaempferol & $\mathrm{Y}=12.338 \mathrm{x}+74.333$ & 0.9991 \\
Luteorin & $\mathrm{Y}=28.215 \mathrm{x}+1349.6$ & 0.9965 \\
Myricetin & $\mathrm{Y}=56.393 \mathrm{x}+938.33$ & 0.9994 \\
Naringenin & $\mathrm{Y}=157.18 \mathrm{x}+5840.3$ & 0.9974 \\
Pelargonidin chloride & $\mathrm{Y}=87.617 \mathrm{x}+5461$ & 0.977 \\
Quercetin & $\mathrm{Y}=20.193 \mathrm{x}+143.83$ & 0.9998 \\
Quercetin 3-D-galactoside & $\mathrm{Y}=218.58 \mathrm{x}+3785.8$ & 0.99978 \\
Rosmarinic acid & $\mathrm{Y}=34.274 \mathrm{x}+751.66$ & 0.9967 \\
Rutin (trihydrate) & $\mathrm{Y}=73.935 \mathrm{x}+1446.5$ & 0.9989 \\
\hline & & \\
\hline & &
\end{tabular}

analysis of total polyphenol, flavonoid and anthocyanin determination and to identify and quantify flavonoids of KWG pomace using a LC/MS/MS. Higher total polyphenol 
Table 4. Flavonoid quantification of whole Korean wild grape and grape pomace by LC/MS/MS

\begin{tabular}{|c|c|c|c|c|}
\hline & \multicolumn{2}{|c|}{$\begin{array}{c}\text { Korean Wild Grape } \\
\text { (Vitis coignetiae) }\end{array}$} & \multirow[b]{2}{*}{$\mathrm{SEM}^{\mathrm{z}}$} & \multirow[b]{2}{*}{$p$-value } \\
\hline & $\begin{array}{l}\text { Whole } \\
\text { grape }\end{array}$ & $\begin{array}{c}\text { Grape } \\
\text { pomace }\end{array}$ & & \\
\hline \multicolumn{5}{|l|}{ Anthocyanin (ng/g) } \\
\hline Cyanin chloride & $11.38^{\mathrm{a}}$ & $0.75^{\mathrm{b}}$ & 3.08 & 0.01 \\
\hline \multicolumn{5}{|l|}{ Flavan-3-ols (ng/g) } \\
\hline Epigallocatechin & 1.48 & $\mathrm{Ta}^{\mathrm{y}}$ & 0.05 & - \\
\hline Epicatechin & $521.69^{\mathrm{a}}$ & $147.58^{\mathrm{b}}$ & 86.85 & 0.01 \\
\hline Gallocatechin & 4.16 & 0.35 & 1.21 & 0.12 \\
\hline \multicolumn{5}{|l|}{ Flavanone (ng/g) } \\
\hline Naringenin & $\mathrm{Ta}$ & 1.66 & 0.73 & - \\
\hline \multicolumn{5}{|l|}{ Flavone $(n g / g)$} \\
\hline Quercetin 3-D-galacto & 17.97 & $\mathrm{Ta}$ & 3.17 & - \\
\hline Rutin(trihydrate) & 305.45 & 110.94 & 61.54 & 0.12 \\
\hline \multicolumn{5}{|l|}{ Flavonol (ng/g) } \\
\hline Isorhamnetin & $1.29^{\mathrm{a}}$ & $0.27^{\mathrm{b}}$ & 0.27 & 0.03 \\
\hline Myricetin & $65.74^{\mathrm{a}}$ & $29.04^{\mathrm{b}}$ & 9.04 & 0.01 \\
\hline Quercetin & 0.24 & 0.42 & 0.06 & 0.12 \\
\hline
\end{tabular}

${ }^{\mathrm{z}} \mathrm{SEM}=$ standard error of the mean.

${ }^{\mathrm{y}} \mathrm{Ta}=$ traceable.

${ }^{\mathrm{a}, \mathrm{b}}$ Mean values within a row followed by different letters indicate significant difference at $p<0.05$.

and flavonoid were determined when $75 \%$ ethanol was used as a grape skin extractant $(p<0.05)$. Additionally, grape pomace contained high total polyphenol, flavonoid and anthocyanin as compared to that of whole grape $(p<0.05)$. A total of 21 flavonoids and non-flavonoids were identified but only 10 flavonoids were quantified in whole grape and grape pomace. Both epicatechin and rutin are main flavonoids confirmed, and they were around 521 and $147 \mathrm{ng} / \mathrm{g}$ of epicatechin and 305 and $110 \mathrm{ng} / \mathrm{g}$ of rutin in both whole grape and grape pomace $(p<0.05)$. Therefore, it seems that KWG pomace is able to be used as a food material, and strategies to include KWG pomace in food products must be founded.

\section{Acknowledgment}

This research was completed with financial support from the basic science research program through the National Research Foundation of Korea (NRF) funded by the Ministry of Education (NRF-2012R1A1A2007394), for which we are deeply appreciative. All authors declare no conflict of interest.

\section{References}

Amico, V., E.M. Napoli, A. Renda, G. Ruberto, C. Spatafora and C. Tringali. 2004. Constituents of grape pomace from the Sicilian cultivar 'Nerello Mascalese'. Food Chem. 88:599-607.

Anesini, C., G.E. Ferraro and R. Filip. 2008. Total polyphenol content and antioxidant capacity of commercially available tea (Camellia sinensis) in Argentina. J. Agric. Food Chem. 56:9225-9229.

Butkhup, L., S. Chowtivannakul, R. Gaensakoo, P. Prathepha and S. Samappito. 2010. Study of the phenolic composition of shiraz red grape cultivar (Vitis vinifera L.) cultivated in north-eastern Thailand and its antioxidant and antimicrobial activity. S. Afr. J. Enol. Vitic. 31:89-98.

Chang, H.Y., Y.B. Lee, H.A. Bae, J.Y. Huh, S.H. Nam, H.S. Sohn, H.J. Lee and S.B. Lee. 2011. Purification and characterization of Aspergillus sojae naringinase: The production of pruning exhibiting markedly enhanced solubility with in vitro inhibition of HMG-CoA reductase. Food Chem. 124:234-241.

Corrales, M., S. Toepfl, P. Butz, D. Knorr and B. Tauscher. 2008. Extraction of anthocyanins from grape by-products assisted by ultrasonics, high hydrostatic pressure or pulsed electric fields: A comparison. Innov. Food Sci. Emerg. Technol. 9:85-91.

FAO STAT Database in http://faostat.fao.org (April 10 ${ }^{\text {th }}, 2014$ ) Faustino, R.S., T.A. Clark, S. Sobrattee, M.P. Czubryl and G.N. Pierce. 2004. Differential antioxidant properties of red wine in water soluble and lipid soluble peroxyl radical generating systems. Mol. Cell Biochem. 263:211-215.

Gong, J.H., I.H. Cho, D. Shin, S.Y. Han, S.H. Park and Y.H. Kang. 2014. Inhibition of airway epithelial-to-mesenchymal transition and fibrosis by kaempferol in endotoxin-induced epithelial cells and ovalbumin-sensitized mice. Lab. Invest. 94:297-308.

Gong, J.H., D. Shin, S.Y. Han, J.L. Kim and Y.H. Kang. 2012. Kaempferol suppresses eosinophil infiltration and airway inflammation in airway epithelial cells and in mice with allergic asthma. J. Nutr. 142:47-56.

Han, S.Y., J.Y. Bae, S.H. Park, Y.H. Kim, J.H. Park and Y.H. Kang. 2013. Resveratrol inhibits IgE-mediated basophilic 
mast cell degranulation and passive cutaneous anaphylaxis in mice. J. Nutr. 143:632-639.

Jang, K.I., J.H. Lee, S.G. Choi and H.B. Lee. 2008. Quality of stored grape (Vitis labruscana) treated with electrolyzed acid water humidification, electrolyzed acid water sterilization and ozone water sterilization. Agric. Life Sci. 42:47-57.

Juan, M.Y. and C.C. Chou. 2010. Enhancement of antioxidant activity, total phenolic and flavonoid content of black soybeans by solid state fermentation with Bacillus subtilis BCRC 14715. Food Microbiol. 27:586-591.

Kammerer, D., A. Claus, R. Carle and A. Schieber. 2004. Polyphenol screening of pomace from red and white grape varieties (Vitis vinifera L.) by HPLC-DAD-MS/MS. J. Agric. Food Chem. 52:4360-4367.

Kammerer, D., A. Claus, A. Shieber and R. Carle. 2005. A novel process for the recovery of polyphenols from grape (Vitis vinifera L.) pomace. J. Food Sci. 70:C157-C163.

Kennedy, J.A. and M.A. Matthews. 2002. Waterhouse AL. Effect of maturity and vine water status on grape skin and wine flavonoids. Am. J. Enol. Vitic. 53:268-274.

Khanal, R.C., L.R. Howard and R.L. Prior. 2009. Procyanidin content of grape seed and pomace, and total anthocyanin content of grape pomace as affected by extrusion processing. J. Food Sci. 74:H174-H182.

Khanal, R.C., L.R. Howard and R.L. Prior. 2010. Effect of heating on the stability of grape and blueberry pomace procyanidins and total anthocyanins. Food Res. Int. 43:14641469.

Lee, M.K., S.S. Moon, S.E. Lee, S.H. Bok, T.S. Jeong, Y.B. Park and M.S. Choi. 2003. Naringenin 7-O-cetyl ether as inhibitor of HMG-CoA reductase and modulator of plasma and hepatic lipids in high cholesterol-fed rats. Bioorg. Med. Chem. 11:393-398.

Lacopini, P., M. Baldi, P. Storchi and L. Sebastiani. 2008. Catechin, epicatechin, quercetin, rutin and resveratrol in red grape: Content, in vitro antioxidant activity and interactions. J. Food Comp. Anal. 21:589-598.

Llobera, A. and J. Cañellas. 2007. Dietary fibre content and antioxidant activity of Manto Negro red grape (Vitis vinifera): pomace and stem. Food Chem. 101:659-666.

Lu, Y. and L.Y. Foo. 1999. The polyphenol constituents of grape pomace. Food Chem. 65:1-8.

Maier, T., M. Fromm, A. Schieber, D.R. Kammerer and R. Carle. 2009. Process and storage stability of anthocyanins and non-anthocyanin phenolics in pectin and gelatin gels enriched with grape pomace extracts. Eur. Food Res. Technol. 229:949-960.

Marinova, D., F. Ribarova and M. Atanassova. 2005. Total phenolics and total flavonoids in Bulgarian fruits and vegetables. J. Univ. Chem. Technol. Metallurgy. 40:255-260.

Meng, X., P. Maliakal, H. Lu, M-J. Lee and C.S. Yang. 2004. Urinary and plasma levels of resveratrol and quercetin in humans, mice and rats after ingestion of pure compounds and grape juice. J. Agric. Food Chem. 52:935-942.

Monrad, J.K., L.R. Howard, J.W. King, K. Srinvas and A. Nauromoustakos. 2010. Subcritical solvent extraction of anthocyanins from dried red grape pomace. J. Agric. Food Chem. 58:2862-2868.

Negro, C., L. Tommasi and A. Miceli. 2003. Phenolic compounds and antioxidant activity from red grape marc extracts. Bioresource Technol. 87:41-44.

Özkan, G., O. Sagdic, N.G. Baydar and Z. Kurumahmutoglu. 2004. Antibacterial activities and total phenolic contents of grape pomace extracts. J. Sci. Food Agric. 84:1807-1811.

Panoutspopoulos, G. and C. Beedham. 2005. Enzymatic oxidation of vanillin, isovanillin and protocatechuic aldehyde with freshly prepared guinea pig liver slices. Cell Physiol. Biochem. 15:89-98.

Park, M.R., Y. Chul, Y.N. Chang and B.Y. Ahn. 2012. Change of total polyphenol content of fermented gastrodia elata blume and radical scavenging. Korean J. Plant Res. 25(4): 379-386.

Pinelo, M., A. Amous and A.S. Meyer. 2006. Upgrading of grape skins: Significance of plant cell-wall structural components and extraction techniques for phenol release. Trends Food Sci. Technol. 17:579-590.

Ratnasooriya, C.C., V. Rupasinghe and A.R. Jamieson. 2010. Juice quality and polyphenol concentration of fresh fruits and pomace of selected Nova Scotia-grown grape cultivars. Can. J. Plant Sci. 90:193-205.

Revilla, E. and J.M. Ryan. 2000. Analysis of several phenolic compounds with potential antioxidant properties in grape extracts and wines by high-performance liquid chromatographyphotodiode array detection without sample preparation. J. Chromatogr. A. 881:169-461.

Ruberto, G., A. Renda, C. Daquino, V. Amico, C. Spatafora, C. Tringali and N. de Tommasi. 2007. Polyphenol constituents and antioxidant activity of grape pomace extracts from five Sicilian red grape cultivars. Food Chem. 100:203-210.

SAS. 1998. SAS Institute, SAS User Guide to Statistics. 
Version 6.12. SAS Inst. Inc., Cary, NC (USA).

Shin, D., H.S. Yang, B.R. Min, C. Narciso-Gaytán, M.X. Sánchez-Plata and C.A. Ruiz-Feria. 2011. Evaluation of antioxidant effects of vitamins $\mathrm{C}$ and $\mathrm{E}$ alone and in combination with sorghum bran in a cooked stored chicken sausage. Korean J. Food Sci. Anim. Resour. 31:693-700.

Spigno, G., L. Tramelli and D.M. de Faveri. 2007. Effects of extraction time, temperature and solvent on concentration and antioxidant activity of grape marc phenolics. J. Food Eng. 81:200-208.

Stevenson, D.E. and R.D. Hurst. 2007. Polyphenolic phytochemicals - just antioxidants or much more? Cell Mol. Life Sci. 64:2900-2916.
Tourtoglou, C., N. Nenadis and A. Paraskevopoulou. 2014. Phenolic composition and radical scavenging activity of commercial Greek white wines from Vitis vinifera L. cv. Malagousia. J. Food Comp. Anal. 33:166-174.

Wu, X., G.R. Beecher, J.M. Holden, D.B. Haytowitz, S.E. Gebhardt and R.L. Prior. 2006. Concentrations of anthocyanins in common foods in the United States and estimation of normal consumption. J. Agric. Food Chem. 31:4069-4075.

Yilmaz, Y. and R.T. Toledo. 2004. Major flavonoids in grape seeds and skins: Antioxidant capacity of catechin, epicatechin, and gallic acid. J. Agric. Food Chem. 52:255-260.

(Received 6 October 2014 ; Revised 19 November 2014 ; Accepted 24 November 2014) 